\section{(6) OPEN ACCESS}

\title{
The prevalence of hepatitis $C$ among healthcare workers: a systematic review and meta-analysis
}

\author{
Claudia Westermann, ${ }^{1}$ Claudia Peters, ${ }^{1}$ Birgitte Lisiak, ${ }^{2}$ Monica Lamberti, ${ }^{3}$ \\ Albert Nienhaus ${ }^{1,2}$
}

- Additional material is published online only. To view please visit the journal online (http://dx.doi.org/10.1136/ oemed-2015-102879).

${ }^{1}$ University Medical Center Hamburg-Eppendorf, Institute for Health Services Research in Dermatology and Nursing, Hamburg, Germany ${ }^{2}$ Institution for Statutory Accident Insurance and Prevention in Health and Welfare Services, Hamburg, Germany

${ }^{3}$ Department of Biochemistry, Biophysics and General Pathology, Second University of Naples, Naples, Italy

\section{Correspondence to} Claudia Westermann, University Medical Center Hamburg-Eppendorf, Institute for Health Services Research in Dermatology and Nursing, Martinistrasse 52, Hamburg 20246, Germany;

c.westermann@uke.de

Received 10 February 2015 Revised 5 August 2015 Accepted 30 August 2015 Published Online First 5 October 2015

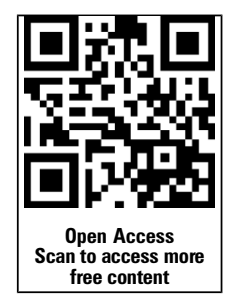

CrossMark

To cite: Westermann $C$, Peters C, Lisiak B, et al. Occup Environ Med 2015;72:880-888.

\section{ABSTRACT}

The aim of this study was to estimate the prevalence of viral hepatitis C (HCV) infection among healthcare workers (HCWs) compared to the general population. A systematic search for the years 1989-2014 was conducted in the Medline, Embase and Cochrane databases. Studies on hepatitis $\mathrm{C}$ in HCWs were included if they incorporated either a control group or reference data for the general population. The study quality was classified as high, moderate or low. Pooled effect estimates were calculated to determine the odds of occupational infection. Heterogeneity between studies was analysed using the $\chi^{2}$ test $(p<0.10)$ and quantified using the $\mathrm{I}^{2}$ test. 57 studies met our criteria for inclusion and 44 were included in the meta-analysis. Analysis of high and moderate quality studies showed a significantly increased $\mathrm{OR}$ for $\mathrm{HCV}$ infection in HCWs relative to control populations, with a value of $1.6(95 \% \mathrm{Cl} 1.03$ to 2.42). Stratification by study region gave an OR of 2.1 in low prevalence countries; while stratification by occupational groups gave an increased prevalence for medical (OR 2.2) and for laboratory staff (OR 2.2). The OR for professionals at high risk of blood contact was 2.7. The pooled analysis indicates that the prevalence of infection is significantly higher in HCWs than in the general population. The highest prevalence was observed among medical and laboratory staff. Prospective studies that focus on HCW-specific activity and personal risk factors for HCV infection are needed.

\section{INTRODUCTION}

Viral hepatitis C (HCV) infection is caused by blood contact and is a public health problem throughout the world. Its clinical course may be severe and can lead to work disability or to death. Considerable costs are incurred for prophylactic and treatment measures and result from the chronic clinical progress of the disease, loss of working hours and premature death. According to the WHO, approximately 150 million people in the world are chronically infected with $\mathrm{HCV}$, and hepatitis $\mathrm{C}$ is the cause of 350000 deaths annually. ${ }^{1} \mathrm{HCV}$ is mainly transmitted by contact with infected blood due to injuries to the skin or mucous membranes. ${ }^{2}$ Acute infection is often asymptomatic and therefore frequently overlooked. In up to $80 \%$ of patients, the clinical course is chronic, leading to an increased risk of developing hepatic cirrhosis or hepatic cell carcinoma. ${ }^{3}$ Risk factors for HCV infection include intravenous drug consumption, injury-prone sex (men with men) and blood transfusions before the introduction of diagnostic testing. There is no vaccine or postexposure prophylaxis for $\mathrm{HCV}$ infection.
Healthcare workers (HCWs) have contact with infected patients and their body fluids. A particularly important factor is repeated performance of exposure prone procedures (EPPs) that may cause injuries to employees. ${ }^{4}$ Injuries to medical and health staff from sharp or pointed objects are among the most frequently reported occupational accidents in healthcare. ${ }^{5}$ The results of epidemiological studies indicate that approximately $80 \%$ of HCWs have been affected by needlestick injuries (NSI). ${ }^{6}$ Many such injuries go unreported..$^{6-8}$ The risk of seroconversion after an injury depends on factors including the type of injury (deep cuts or pricks), the quantity of infectious material transferred, the virus load in the index patient and possibly genetic factors in the injured person. ${ }^{8-10}$

The probability of HCV seroconversion after a NSI in Europe has been estimated as $0.42 \% .^{6}{ }^{8}$ Although HCV infection as an occupational disease is statistically rare, the consequences for the HCW and the health system are considerable. ${ }^{71} 12$ In 2012, $79 \mathrm{HCV}$ infections were reported to the German Institution for Statutory Accident Insurance and Prevention in Health and Welfare Services, and 47 infections were recognised as occupational diseases. ${ }^{13}$ Numerous studies have investigated the prevalence of $\mathrm{HCV}$ in $\mathrm{HCW}$ s, but the results have been inconsistent. The objective of the present study is to estimate the prevalence of HCV infection among HCWs compared to the general population. Which professionals are particularly affected by infection?

\section{METHODS}

This study is reported in line with the Proposal for Reporting of Meta-analyses of Observational Studies (MOOSE). ${ }^{14}$

\section{Search strategy and screening}

A systematic literature search was performed in the Medline, Embase and Cochrane databases for the period from 1989 to 2014. This included all prevalence and incidence studies on hepatitis $\mathrm{C}$ in $\mathrm{HCW}$ with either a control group or reference data on the general population. The Embase search was performed using the following search terms: ((()('hepatitis C’) AND 'occupational exposure’) AND 'healthcare worker') AND prevalence) OR incidence)-with and without truncation (see online supplementary file). The search strategy was adapted for the other databases. Additionally, we searched reference lists of the chosen studies and prior reviews. Where it was not possible to make a decision on a study's inclusion or exclusion based on the abstract, the full text of the study was 
examined. The studies were screened and their quality was assessed by two reviewers working independently and using predefined checklists. Disagreements were resolved by consensus.

Studies meeting the following criteria were considered for inclusion:

- Population: HCWs in direct contact with patients or blood

- Exposure: Study examines occupational exposure

- Control: Control group/reference data for general population from other publications

- Outcome: Serological test for HCV

- Design: Prevalence and incidence studies

- Languages: German, English, French, Spanish, Portuguese, Italian.

The following criteria led to exclusion from this study:

- Population: HCWs without direct contact with patients or blood

- Exposure: No occupational exposure

- Control: No control group; reference data for the general population not taken from other publications

- Outcome: No serological test for HCV

- Design: Case reports, surveillance data.

In studies with several control groups, the ones selected were those that best reflected the general population. Studies that examined HCWs without a control group were only included when the results were compared with a population-based study performed within a period of 2 years before or after the actual investigation and in a comparable study region.

In this report, 'healthcare worker' (HCW) is defined as any person (eg, an employee or student) whose activities involve contact with patients or with blood or other body fluids from patients in a healthcare setting. ${ }^{15}$

\section{Study quality}

In accordance with the literature, we developed an instrument to assess the methodological quality of the observational studies included. ${ }^{16-20}$ Scores were awarded on the basis of the criteria below. A total of nine scores was possible (table 1).

Quality of the laboratory test: Anti-HCV detection depends on the type of test used, and tests differ in quality (product and procedure). In order to standardise the quality assessment, we evaluated the presence of a confirmatory test, but not its quality or procedure. It was not possible to evaluate this in the primary studies, due to missing data.

\section{Statistical analysis}

For the meta-analysis, data were extracted from the studies using a standardised documentation form. The parameters were

Table 1 Checklist for quality assessment

\begin{tabular}{llll}
\hline Item & Criterion & Content & Score \\
\hline 1 & Aim & A clearly stated aim & 1 \\
2 & Sample size & $>50$ persons & 1 \\
3 & Response rate & $>50 \%$ & 1 \\
4 & Length of & Information is available & 1 \\
& employment & & 1 \\
5 & Control group & A control group was tested & 1 \\
7 & Confounder & Adjusted for potential confounders & 1 \\
8 & Limitations & Were discussed & 1 \\
& Laboratory tests & Performance of anti-HCV test or PCR test & 1 \\
\hline $8-9$ scores=high; $5-7$ scores=moderate; $\leq 4$ scores=low. \\
HCV, viral hepatitis C.
\end{tabular}

the number of employees examined and the proportion of employees tested as serologically positive. Prevalence ratios (ORs) were calculated as effect estimates using the Mantel-Haenszel method for dichotomous outcomes. The 95\% CIs were generated. Additional analyses were performed after stratification by type of controls, study region, publication period, gender and professional group. Meta-analyses were carried out using Review Manager 5.2.

In accordance with the criteria of Trevisan et al, ${ }^{50}$ a pooled analysis was performed for professionals exposed to a high risk of blood contact from EPPs. This analysis included the following professions/working areas: surgeons, midwives, microbiologists, pathologists, blood bank and dialysis staff.

Stratification by study region was performed on the basis of national prevalence rates. Based on the publications of $\mathrm{Te}$ and Jensen, ${ }^{3}$ Hahne et $a l^{21}$ and Mohd Hanafiah et al, ${ }^{22}$ pooled effect estimates were calculated for low prevalence countries taking into account countries of north-west Europe and the USA. Studies from Japan were analysed separately as there have been reports that the rate of seroconversion is higher in Japan than in Europe. ${ }^{8}$

Studies that observed no HCV infection in either group were excluded from the meta-analysis as no information about the relative probability of the event could be derived. ${ }^{18}$

\section{Heterogeneity and sensitivity analysis}

The presence of heterogeneity was tested using the $\chi^{2}$ test, taking $\mathrm{p}<0.10$ as the level of significance. An $\mathrm{I}^{2}$ test was performed to quantify the diversity between studies. If there was no evidence of heterogeneity, we used a variance approach with a fixed effect model. ${ }^{18}$ In cases of statistically significant heterogeneity $\left(\chi^{2} \mathrm{p}\right.$ value $\left.<0.10\right)$ and $\mathrm{I}^{2}>50 \%$, the pooled effect estimate was determined using the random effect model. To identify sources of variation, further stratification was performed relative to study quality and to performance of confirmatory tests. In addition, for the sensitivity analyses, the stability of the pooled estimate with respect to each study was investigated by excluding individual studies from the analysis.

\section{Publication bias}

Possible publication bias was visualised with a funnel plot. In addition, the probability of publication bias was tested using Egger's linear regression in SPSS V.20. ${ }^{23}$ The level of significance for asymmetry was taken as $\mathrm{p}<0.1$. The calculated intercept is given with a $90 \%$ confidence range.

\section{RESULTS}

A total of 3016 publications were identified in the databases and 41 by manual search. After checking for duplicates, the titles and abstracts of 954 studies were screened, leading to the exclusion of 801 studies. The full texts of 153 studies were scrutinised and 57 studies were included in the systematic review. This selection process is given in figure 1 .

Table 2 gives an overview of the studies included. A total of 27 studies from Europe were included, along with 13 from Asia, eight from Africa, seven from North America and two from South America. In most studies, HCWs were examined within the inter-professional framework. In five studies, the HCWs were stratified by professional group and, in five studies, by working area or exposure. Ten studies examined only a single professional group.

In 33 out of 57 studies, population-based controls, consisting mainly of blood donors, were used. A hospital control group was used in 18 studies. Ciorlia and Zanetta ${ }^{38}$ used a population- 


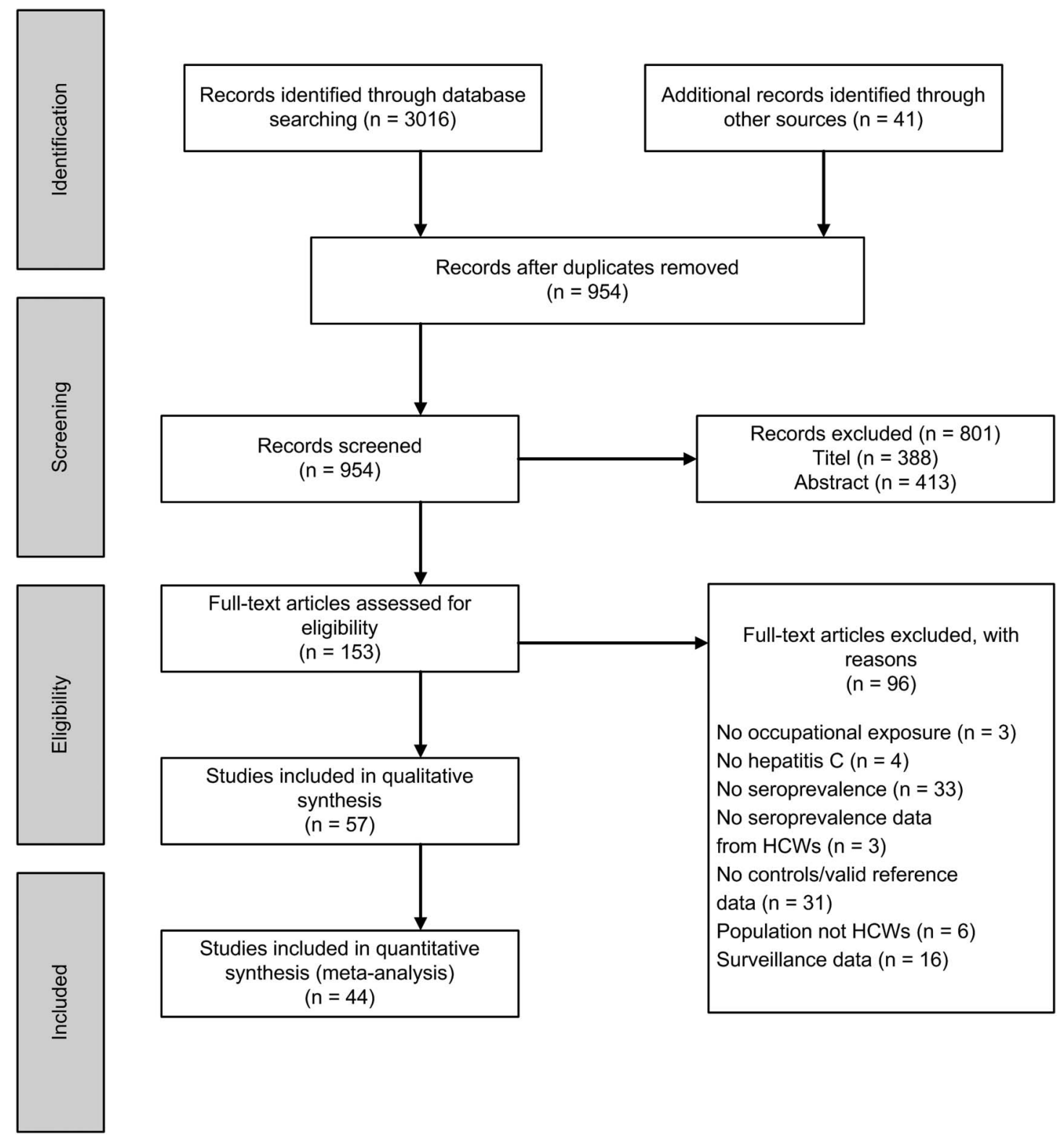

Figure 1 Selection process. HCWs, health care workers.

based and a hospital control group. Four studies used a population control and several other control groups, including risk groups such as dialysis patients and men who have sex with men.

\section{Study design and quality}

Fifty-one studies had a retrospective design and six a prospective design. $^{24-29}$ The annual incidence was reported in two studies only. According to Puro et al, ${ }^{24}$ the rate was $0.1 \%$; and $0.15 \%$ according to Cooper et al. ${ }^{26}$

The methodological quality was rated as high in seven studies, as moderate in 33 studies and as poor in 17 studies.

\section{HCV detection}

A HCV confirmation test was performed in 37 studies. Five studies used the same test for the confirmation as for the first test. There were differences between the studies with respect to the quality of the tests used (table 2).
HCV exposure among HCWs-a qualitative summary of studies not included in the meta-analysis

Thirteen studies could not be included in the meta-analysis because of missing case numbers (table 2). Increased HCV seroprevalence in HCWs in comparison to population controls was found in four out of seven studies of moderate methodological quality and in three out of six studies of low methodological quality. Cooper et $a l,{ }^{26}$ Goetz et $a l^{53}$ and Zaaijer et $a l^{66}$ studied employees stratified by their exposure risk. All seropositive employees worked in areas with high exposure to blood contact (eg, dialysis, blood bank, laboratory), or reported prior NSI. ${ }^{26}$ With the exception of Mijakoski et al, ${ }^{73}$ all controls were from reference sources.

\section{Meta-analysis}

The main results are shown as plots in figure 2. Further results of pooling analyses and subgroup analyses are summarised in online supplementary table S3. 
Table 2 Characteristics of studies included

\begin{tabular}{|c|c|c|c|c|c|c|c|c|c|c|}
\hline Author/year & Country & Period & HCV tests & HCWs & $n(n+)$ & Prevalence \% & Controls & $n(n+)$ & Prevalence \% & $\begin{array}{l}\text { Study quality } \\
\text { (scores)* }^{*}\end{array}$ \\
\hline \multicolumn{11}{|l|}{ Prospective studies } \\
\hline Puro $1995^{24}$ & Italy & 1992-1993 & Anti-HCV 2, enzyme immunoassay RIBA 2 & $S$ & $3073(67)$ & 2.2 & $\operatorname{Pr}$ & $11000(19)$ & 1.7 & High $(8)^{1-4} 6-8$ \\
\hline Maillard $1996^{25}$ & France & 1992-1993 & ELISA 2, PCR & $S$ & $236(7)$ & 2.9 & $\mathrm{H}$ & $305(2)$ & 0.7 & Moderate $(6)^{12578}$ \\
\hline Cooper+1992 ${ }^{26}$ & USA & NA & $\begin{array}{l}\text { EIA } \\
\text { RIBA } 2\end{array}$ & $S \ddagger$ & $243(4)$ & 1.6 & $\operatorname{Pr}$ & - & $0.4-1.4$ & Moderate $(6)^{12478}$ \\
\hline Ahmetagic $2006^{27}$ & $\begin{array}{l}\text { Bosnia and } \\
\text { Herzegovina }\end{array}$ & 2003-2005 & ELISA 3, HCV-RNA & 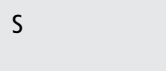 & $1699(6)$ & 0.4 & $P$ & $2000(4)$ & 0.2 & Low $(4)^{1258}$ \\
\hline Daw $2002^{28}$ & Libya & 1999-2001 & ELISA & s & $459(9)$ & 2 & $\mathrm{P} \S$ & $1200(14)$ & 1.2 & Low $(4)^{1258}$ \\
\hline Mihalyt $2001^{29}$ & Hungary & 1986-1998 & EIA 2, EIA 3, RIBA 3, PCR & M, NS, CS $\ddagger$ & $477(13)$ & 2.7 & $\operatorname{Pr}$ & - & $0.73-1$ & Low $(4)^{128}$ \\
\hline \multicolumn{11}{|l|}{ Retrospective studies } \\
\hline Gershon $2007^{30}$ & USA & 1999-2000 & HCV 2, RIBA 3 & s & $216(4)$ & 1.9 & $\mathrm{H}$ & $94(3)$ & 3.2 & High $(9)^{1-8}$ \\
\hline Ozsoy $2003^{31}$ & Turkey & $1998-2000$ & Anti-HCV 3 IL, INNOTEST 3, RT-PCR, ELISA & $\mathrm{s}$ & $702(2)$ & 0.3 & $P$ & $5670(23)$ & 0.4 & High $(9)^{1-8}$ \\
\hline Klein $1991^{32}$ & USA & 1985-1987 & ELISA 1, RIBA & D & $456(8)$ & 1.8 & $P$ & $723(1)$ & 0.1 & High $(9)^{1-8}$ \\
\hline Sermoneta-Gertel $2001^{33}$ & Israel & 1995-1997 & EIA 3, RIBA 3 & $\mathrm{~s}$ & 3657 (34) & 0.9 & $\mathrm{H}$ & $630(3)$ & 0.5 & High $(8)^{1-4} 6-8$ \\
\hline Thomas $1996^{34}$ & USA & 1991 & ELISA 1 or ELISA 2, RIBA & NS & $943(7)$ & 0.7 & $P$ & $104,239(417)$ & 0.4 & High $(8)^{1-578}$ \\
\hline Struve $1994^{35}$ & Sweden & NA & EIA 2, Supplementary test & M, NS, Lף & $797(5)$ & 0.6 & $\mathrm{H}$ & $83(1)$ & 1.2 & High $(8)^{1-578}$ \\
\hline Braczkowska $2006^{36}$ & Poland & 2003-2004 & ELISA 3, Westem blot LIA HCV Ab3 & MS & $558(8)$ & 1.4 & $P$ & $510(2)$ & 0.4 & Moderate $(7)^{1-3568}$ \\
\hline Fisker $2004^{37}$ & Denmark & 1998 & HCV 3, RIBA, PCR & $\mathrm{s}$ & $960(2)$ & 0.2 & $\mathrm{H}$ & $479(0)$ & - & Moderate $(7)^{1-58}$ \\
\hline Ciorlia $2007^{38}$ & Brazil & 1994-1999 & ELISA 2 & $s$ & $1433(25)$ & 1.7 & $\mathrm{H}, \mathrm{P}$ & $\begin{array}{l}872(4) \\
2583(6)\end{array}$ & $\begin{array}{l}1.3 \\
0.2\end{array}$ & Moderate $(7)^{1-68}$ \\
\hline Moens $2000^{39}$ & Belgium & 1996-1997 & EIA 3, Matrix Abbott und LIA, PCR & $S \ddagger$ & $4480(21)$ & 0.4 & $\mathrm{H}$ & $426(0)$ & - & Moderate $(7)^{1-36-8}$ \\
\hline Thorburn $2001^{40}$ & Scotland & 1994-1996 & ELISA 3, PCR, RIBA-3 & $S, D$ & $\begin{array}{l}10,654 \\
(27)\end{array}$ & 0.3 & $\mathrm{H}$ & $471(3)$ & 0.6 & Moderate $(7)^{1-35} 58$ \\
\hline Djeriri $1996^{41}$ & France & 1993-1994 & $\begin{array}{l}\text { EIA } 2 \\
\text { RIBA2 }\end{array}$ & $S$ & $283(2)$ & 0.7 & $\mathrm{H}$ & $93(0)$ & - & Moderate $(7)^{1-3568}$ \\
\hline Villate $1993^{42}$ & Spain & 1991-1992 & ELISA 2, PCR, RIBA 2 & $M, L, N S ף$ & $874(14)$ & 1.6 & $P$ & $547(2)$ & 0.4 & Moderate $(7)^{1-58}$ \\
\hline Montella $2005^{43}$ & Italy & 1991 & ELISA 1,ELISA new generation & M, NS, Lף & $578(32)$ & 5.5 & $\mathrm{H}$ & $91(6)$ & 6.6 & Moderate $(7)^{124-68}$ \\
\hline Kaabia $2009^{44}$ & Tunisia & 2005 & ELISA Murex 4, ELISA AxSYM Abbott & $M, L, P, M w ף$ & 737 (9) & 1.2 & $\mathrm{H}$ & $104(0)$ & - & Moderate $(6)^{1-358}$ \\
\hline Irani-Hakime $2001^{45}$ & Lebanon & 1999 & SM-HCV rapid test, MEIA HCV 3, PCR & s & $502(2)$ & 0.4 & $P$ & $600(1)$ & 0.2 & Moderate $(6)^{1-3} 58$ \\
\hline Campello $1992^{46}$ & Italy & 1989-1990 & ELISA, HCV neutralisation test & $s$ & $407(5)$ & 1.2 & $P$ & $253(2)$ & 0.8 & Moderate $(6)^{12458}$ \\
\hline Polish $1993^{47}$ & USA & 1983 & $\begin{array}{l}\text { Anti-HCV } 1 \text { Abbott, HCV neutralisation } \\
\text { assay Abbott }\end{array}$ & $\mathrm{s}$ & $1350(22)$ & 1.6 & $\mathrm{H}$ & $257(1)$ & 0.4 & Moderate $(6)^{12568}$ \\
\hline Perez Trallero $1992^{48}$ & Spain & NA & ELISA 2, RIBA 2 & $s$ & $251(4)$ & 1.6 & $P$ & $377(8)$ & 2.1 & Moderate $(6)^{12458}$ \\
\hline Takahama $2005^{49}$ & Brazil & NA & ELISA 3, PCR, AxSym Abbott 3 & D & $267(1)$ & 0.4 & $P$ & $88,241(304)$ & 0.3 & Moderate $(6)^{12478}$ \\
\hline Trevisan $1999^{50}$ & Italy & NA & EIA, RIBA 3 & s & $809(9)$ & 1.1 & $\mathrm{H}$ & $408(8)$ & 2 & Moderate $(6)^{12458}$ \\
\hline Webert $2001^{51}$ & Switzerland & 1999 & EIA, EIA3, PCR, Immunoblot & D, DS & $1056(1)$ & 0.1 & $\operatorname{Pr}$ & - & $0.5-1$ & Moderate $(6)^{12478}$ \\
\hline Shapirot $1996^{52}$ & USA & 1991 & $\begin{array}{l}\text { Immunoassay } 1 \text {, supplementary } \\
\text { neutralisation assay }\end{array}$ & M & $3262(27)$ & 0.8 & $\operatorname{Pr}$ & - & $0.09-0.36$ & Moderate(6) ${ }^{12478}$ \\
\hline Goetz† $1995^{53}$ & USA & NA & EIA 2, RIBA 2, Ortho, PCR & $M, D, N S, L \neq$ & $241(5)$ & 1.3 & $\operatorname{Pr}$ & - & 0.3 & Moderate $(6)^{12478}$ \\
\hline Ahmed $2012^{54}$ & Pakistan & 2007-2009 & ETI-AB-HCV-4 & $s$ & $41(7)$ & 17.1 & $P$ & $1959(103)$ & 5.3 & Moderate $(5)^{14-8}$ \\
\hline Fischer $2000^{55}$ & USA & 1998 & PCR & s & $502(0)$ & - & $\mathrm{H}$ & $926(2)$ & 0.2 & Moderate $(5)^{12578}$ \\
\hline De Mercato $1996^{56}$ & Italy & 1995 & RIBA 2 & $s$ & $472(12)$ & 2.5 & $P$ & $285(8)$ & 2.8 & Moderate $(5)^{12458}$ \\
\hline
\end{tabular}


Table 2 Continued

\begin{tabular}{|c|c|c|c|c|c|c|c|c|c|c|}
\hline Author/year & Country & Period & HCV tests & HCWs & $n(n+)$ & Prevalence \% & Controls & $n(n+)$ & Prevalence \% & $\begin{array}{l}\text { Study quality } \\
\text { (scores)* }^{*}\end{array}$ \\
\hline Olubuyide $1997^{57}$ & Nigeria & 1995 & HCV 3-enzyme Immunoassay Murex & $M, D$ & $75(8)$ & 10.7 & $P$ & $25(3)$ & 12 & Moderate $(5)^{12478}$ \\
\hline Al-Sohaibani $1995^{58}$ & Saudi Arabia & 1992-1994 & $\begin{array}{l}\text { UBI HCV EIA, } \\
\text { RIBA or LiaTEK HCV } 3\end{array}$ & M, MSף & $330(8)$ & 2.4 & $P$ & $292(5)$ & 1.7 & Moderate $(5)^{1} 258$ \\
\hline Soni $1993^{59}$ & South Africa & 1991 & EIA 2, EIA 2, Abbott neutralisation EIA & NS & $212(0)$ & - & P§ & $35685(92)$ & 0.3 & Moderate $(5)^{1258}$ \\
\hline Oguchi $1992^{60}$ & Japan & 1989 & ELISA 1 or 2 , & $S$ & $150(3)$ & 2 & $P$ & $704(7)$ & 1 & Moderate $(5)^{12} 458$ \\
\hline Nakashima $1993^{61}$ & Japan & 1987-1988 & $\begin{array}{l}\text { ELISA, } \\
\text { RIBA }\end{array}$ & $S$ & $1097(11)$ & 1 & $P$ & $526(5)$ & 1 & Moderate (5) 1258 \\
\hline Fujiyama $1992^{62}$ & Japan & NA & ELISA anti-C100 & $s$ & $152(1)$ & 0.7 & $P$ & 919 (14) & 1.5 & Moderate $(5)^{1258}$ \\
\hline Germanaud $^{* *} 1994^{63}$ & France & NA & ELISA 2, RIBA 2 & $S$ & $430(4)$ & 0.9 & H & $180(3)$ & 1.7 & Moderate $(5)^{1258}$ \\
\hline Jindalt $2006^{64}$ & India & 2003 & Hep-Chex C & $s$ & $100(4)$ & 4 & $\operatorname{Pr}$ & - & 1.6 & Moderate $(5)^{12-48}$ \\
\hline Kuot $1993^{65}$ & Taiwan & 1990-1991 & EIA 1, EIA 2, PCR & D & $461(3)$ & 0.7 & $\operatorname{Pr}$ & - & 1 & Moderate $(5)^{1248}$ \\
\hline Zaaijer† $2012^{66}$ & The Netherlands & 2000-2009 & AxSYM HCV, RIBA 3, PCR & $S \ddagger$ & 729 (1) & 0.1 & $\operatorname{Pr}$ & - & 0.6 & Moderate $(5)^{1278}$ \\
\hline Zuckermant $1994^{67}$ & Scotland & 1986, 1991 & EIA 2, RIBA 2 & s & $1053(3)$ & 0.3 & $\operatorname{Pr}$ & - & 0.3 & Low $(4)^{128}$ \\
\hline Jochen** $1992^{68}$ & Germany & 1992 & EIA 2, Immunoblot 2 & $s$ & $1033(6)$ & 0.6 & $P$ & $2113(5)$ & 0.2 & Low $(4)^{258}$ \\
\hline El Gohary $1995^{69}$ & Egypt & 1990-1992 & EIA 2 & $S$ & $78(6)$ & 7.7 & $P \S$ & $271(39)$ & 14.4 & Low $(4)^{1258}$ \\
\hline Polywka $1991^{70}$ & Germany & NA & ELISA & $s$ & $217(6)$ & 2.8 & $P$ & $500(2)$ & 0.4 & Low $(4)^{1258}$ \\
\hline Hindy $1995^{71}$ & Egypt & NA & ELISA, Abbott, ALT & DS & $70(1)$ & 1.4 & H & $35(6)$ & 17.1 & Low $(4)^{148}$ \\
\hline Khan $2011^{72}$ & Pakistan & NA & Immunochromatography test, PCR & $s$ & $794(34)$ & 4.3 & H & $30(0)$ & - & Low $(4)^{1248}$ \\
\hline Mijakoskit $2012^{73}$ & Macedonia & NA & anti-HCV Ab & NS & $54(0)$ & - & H & $32(0)$ & - & Low $(4)^{1458}$ \\
\hline Kondili $2007^{74}$ & Albania & NA & EIA 3 & $S$ & $460(3)$ & 0.7 & H & $22(0)$ & - & Low $(3)^{158}$ \\
\hline Libanore $^{* *} 1992^{75}$ & Italy & NA & Immunoassay & 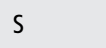 & $1008(41)$ & 4.1 & $\operatorname{Pr}$ & $3572(34)$ & 1 & Low $(4)^{1258}$ \\
\hline Mujeebt $1998^{76}$ & Pakistan & NA & EIA & 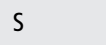 & $114(5)$ & 4.4 & $\operatorname{Pr}$ & - & 0.7 & Low $(4)^{1248}$ \\
\hline Sarkarit $2012^{77}$ & Iran & 2009-2010 & ELISA 3 & $S$ & $212(9)$ & 4.2 & $\operatorname{Pr}$ & - & $0.1-0.9$ & Low $(4)^{1278}$ \\
\hline Vardas $2002^{78}$ & South Africa & 1996 & ELISA 3, PCR & $S$ & $362(7)$ & 1.9 & H & $37(0)$ & - & Low $(3)^{128}$ \\
\hline Shoaeit $2012^{79}$ & Iran & 2010 & ELISA & L & $203(0)$ & - & $\operatorname{Pr}$ & - & 0.2 & Low $(3)^{128}$ \\
\hline De Luca** $1992^{80}$ & Italy & 1990 & NA & $\mathrm{s}$ & $945(45)$ & 4.8 & P§ & 3575 (39) & 1.1 & Low $(2)^{25}$ \\
\hline
\end{tabular}

() In bold letters: cases confirmed by second test.

Fulfilled item for quality assessment-see table 1.

†Not included in meta-analysis.

+Stratified by working area/exposure.
§Further control groups NA.

SFurther control groups NA.
IStratified by professional groups.

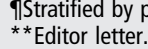

"*Editor letter.

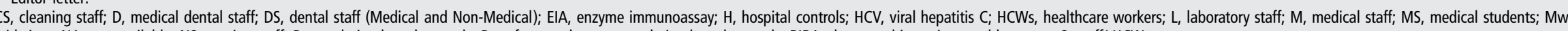
midwives; NA, not available; NS, nursing staff; P, population-based controls; Pr, reference data on population-based controls; RIBA, the recombinant immunoblot assay; $S$, staff/ HCWs. 
A total of 44 studies were included in the pooled analysis (seven high quality studies, 26 moderate quality studies and 11 low quality studies-table 2). The pooled analysis of all studies showed a significantly increased OR of 1.5 (95\% CI 1.15 to 2.06) for a HCV infection among HCWs compared to controls, with significant evidence of heterogeneity $\left(\chi^{2}=110.8, p<0.001\right.$,
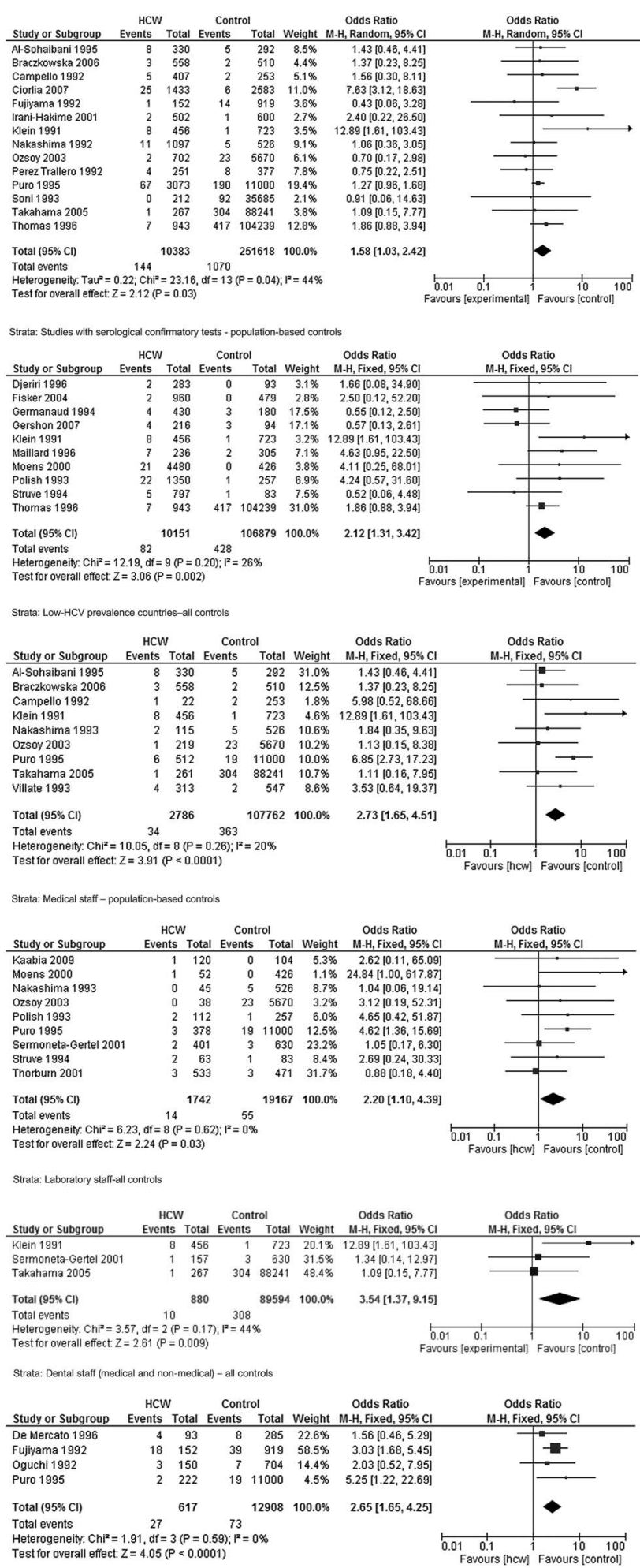

Thete: Combining professionals at high rick for blood contects - population hased controb

Figure 2 Forest plots of high and moderate quality studies on hepatitis $\mathrm{C}$ among healthcare workers. HCWs, health care workers.
$\mathrm{I}^{2}=61$, see online supplementary table S3). The increased prevalence of HCV infection in HCWs was also observed in the 14 studies with high and moderate methodological quality, using population control groups and confirmatory tests (OR 1.6; 95\% CI 1.03 to 2.42, no evidence of heterogeneity, figure 2).

After stratification by publication period, HCWs were found to have a statistically significant increased prevalence of $\mathrm{HCV}$ infection in the period 1989-2000 compared with all controls (OR 1.3; 95\% CI 1.09 to 1.63). For the period 2000-2014, the pooled effect estimate was the same, but without a statistically significant increase (OR 1.3; 95\% CI 0.89 to 2.02). As there are only a few current studies, it was not possible to conduct a test for time trend by subgroups (see online supplementary table S3).

The following analyses were based on high and moderate quality studies only.

\section{Study region}

Pooled analysis of studies from countries with comparably low HCV prevalence in Europe (Belgium, Denmark, France, Scotland, Sweden) and the USA showed a significantly increased prevalence of HCV infection in HCWs compared with controls (OR 2.1; 95\% CI 1.31 to 3.42, figure 2). Further stratification by population-based controls could not be performed because of considerable variability between the studies $\left(\mathrm{I}^{2}=70\right)$. Pooled analysis of Japanese studies showed no increased HCV prevalence in HCWs (OR 1.1). Stratification of studies from the other countries by individual regions resulted in a statistically significant increased HCV prevalence in HCWs only for North Africa, the Middle East and South Asia (OR 1.9; 95\% CI 1.10 to 3.15), compared to controls (see online supplementary table S3).

\section{Gender}

Six studies reported anti-HCV prevalence stratified by gender. By pooling studies using population-based controls with confirmatory tests, a significantly increased prevalence was observed only for male HCWs (women OR 1.5 ; 95\% CI 0.45 to 5.24 ; men OR 3.1 ; $95 \%$ CI 1.21 to 7.99 ).

\section{Professions}

Medical staff: For medical personnel, pooled analysis of studies with confirmatory tests gave an OR of 2.7 (95\% CI 1.65 to 4.51, figure 2). For medical staff excluding dentists, the OR was 2.2 (95\% CI 1.30 to 3.77$)$ for a HCV infection compared to population-based controls (see online supplementary material table S3).

Dental staff (medical and non-medical): Pooled analysis of studies with confirmatory tests gave an OR of 3.5 (95\% CI 1.37 to 9.15 , figure 2) for a HCV infection among dental staff compared to controls. Further stratification could not be performed because of considerable variability between the three studies.

Nursing staff: The pooled analysis of studies with confirmatory tests showed an OR of 1.7 (95\% CI 0.86 to 3.31) for nursing staff compared to the population-based controls (see online supplementary table S3).

Laboratory staff: Pooled analysis of studies with confirmatory tests gave an increased OR of 2.2 (95\% CI 1.10 to 4.39, figure 2) for a $\mathrm{HCV}$ infection in laboratory staff compared with all controls.

Professionals at high risk for blood contacts: Six sources contributed data on the following professions/working areas performing EPPs: surgeons, midwives, microbiologists, pathologists, blood bank and dialysis staff. All studies were published before 2000. The pooled analysis shows a statistically significant increased OR of 2.3 (95\% CI 1.51 to 3.54$)$ for a HCV infection 
among HCWs compared with all controls and of 2.7 (95\% CI 1.84 to 5.53 , figure 2) compared to population-based controls.

\section{Heterogeneity and sensitivity analysis}

Heterogeneity was present when pooling all studies. Pooling the studies with high and moderate methodological quality only, reduced heterogeneity. Further stratification was performed related to performance of confirmatory tests. In addition, individual studies were then sequentially excluded from the analysis in order to verify their influence on the pooled estimate.

\section{Publication bias}

The funnel plot did not show evidence of publication bias (see online supplementary figure S3), nor did Egger's linear regression show significant evidence of funnel plot asymmetry (intercept $0.19,90 \%$ CI 0.33 to $0.71, \mathrm{p}=0.47$ ).

\section{DISCUSSION}

This is the first systematic review to perform a meta-analysis on the prevalence of HCV infection among HCWs in comparison to controls. The pooled analysis of high and moderate quality studies gave a statistically significant increase in OR of 1.6 for $\mathrm{HCV}$ infection among HCWs compared to population-based controls. Stratified pooled analysis of studies with confirmatory tests from countries with comparable low HCV prevalence also resulted in a statistically significant increase in OR for HCWs in comparison to controls (OR 2.1). Stratification by occupational groups demonstrated an increased prevalence among medical staff (OR 2.2), laboratory staff (OR 2.2) and dental staff (medical and non-medical, OR 3.5), compared to controls. However, due to the few studies found for dental staff, further stratification by profession could not be performed. In addition, the pooled effect estimated is mainly caused by one high quality study with a wide CI. ${ }^{32}$ When the pooled analysis was stratified by nursing staff, no significant increase in OR was found. A differentiated examination of activity profile-related occupational hazards was carried out for this profession in only a few studies. This lack of differentiation may lead to underestimation of the occupational risk of infection due to exposure misclassification. This happens particularly when HCWs who are frequently exposed to blood while performing EPPs are examined in combination with less exposed HCWs in the same job category. Pooled analysis for each individual group — such as cleaning staff -was not possible as the studies were few and their methods heterogeneous in design, HCWs examined, serological testing and controls. This diversity is the main reason for the lack of consensus in the assessment of the occupational risk of $\mathrm{HCV}$ infection in HCWs. ${ }^{81-83}$ Additionally, it is difficult to quantify the occupational risk given to a specific profession, such as for laboratory staff, as there is no systematic record of how exposure depends on the activity. ${ }^{84}$ To estimate HCV prevalence in HCWs due to specific work profiles, we conducted an exemplary pooled analysis of professions that performed EPPs in accordance with the criteria of Trevisan et al. ${ }^{50}$ The pooled analysis shows a significantly increased OR of 2.7 for these employees in comparison to the population-based controls. However, the results of this subgroup analysis are based only on studies published before 2000. The assessment of personal risk factors for a HCV infection was not performed consistently in the investigated studies, particularly in studies published earlier. Those examinations were conducted prior to the Needlestick Safety and Prevention Act (NSPA). Both in the USA and in Europe, guidelines have been issued since 2000 that aim to prevent exposure to blood, for example, from NSI. ${ }^{65}$
The results of studies that could not be included in the quantitative analysis did not conflict with the results of the meta-analysis. Professions that performed EPPs are exposed to NSI, with a HCV transmission rate of $1.8 \%$ after an NSI according to Henderson, ${ }^{83}$ Riddell and Sherrard, ${ }^{86}$ and Baldo et al. ${ }^{87}$ The results of an American multicentre study performed in 2006 showed that occupational exposure was greater in male HCWs. ${ }^{88}$ The authors observed that men were three times more frequently infected than their female colleagues. In this context, bivariate analysis showed that glove use when performing invasive work was significantly associated with the female gender. According to the reviews of Kubitschke et $a l^{8}$ and Goniewicz et $a l,{ }^{89}$ NSIs were more frequent in inexperienced personnel. Current findings on the incidence of NSI in the health service show that nursing ${ }^{689}{ }^{90}$ and medical personnel ${ }^{88}$ are the most frequently affected professional group. According to Butsashvili et $a l^{88}$ the highest number of exposures to NSI is in dialysis work. The most recent research on dialysis staff (2006-2010) concluded that there had been no decrease in the number of observed NSIs suffered by staff. ${ }^{6}$

\section{Strengths and limitations}

This is the first meta-analysis to examine the prevalence of HCV infection in HCWs compared to controls. However, the mostly retrospective studies included some recent studies. In addition, older studies tend to report higher anti-HCV prevalence rates than more recent studies (as confirmed by Larney et $a l^{91}$ ). As there are only a few current studies, it was not possible to draw reliable conclusions about a time trend. Most of the populationbased controls were blood donors. Individuals at risk of HCV infection in the general population were probably not included. The results of the studies that referred to reference populations must also be viewed critically. HCWs and controls may not have been tested under identical conditions. Few studies have examined how occupational hazards depend on the activity profile. This lack of differentiation may lead to underestimation of the occupational risk of infection for specific HCWs. So, the present results reveal a strong demand for further differentiated research.

\section{Quality of serological testing}

The quality of the confirmatory tests used clearly differs between individual studies. This is due to the development of better detection methods over time, the quality of the procedure or the fact that there is no fundamental difference between the antigens used in the screening and the confirmatory tests. Owing to the limitations in the sensitivity of the first anti-HCV tests (false negatives), earlier studies tended to underestimate seroprevalence. In contrast, limitations in specificity lead to false positive results. This may result in non-differential misclassification, which again is most likely to lead to decreased effect estimates.

\section{Assessment of personal risk factors}

The personal risk factors for HCV infection were not recorded consistently in the studies. The risk factors, such as use of injected drugs and injury-prone sex (men with men) were not collected in many studies, especially the earlier ones. The 1998 report of the US Center for Disease Control and Prevention (CDC) on the known risks of HCV infection identified drug use and injury-prone sex as the most common causes. ${ }^{15}$ Of the six studies that allow stratification by gender, only two examined these confounding factors, which are associated with a higher 
risk of non-occupationally acquired $\mathrm{HCV}$ infection, especially among men. ${ }^{32} 36$

\section{CONCLUSION}

This meta-analysis shows a statistically significant increase in the prevalence of $\mathrm{HCV}$ infection in HCWs compared to controls. Medical and laboratory personnel, and staff members who perform EPPs, are particularly affected. For other professions, no adequate calculation of a pooled estimate was possible. Prevalence of HCV infection has probably decreased since 2000 , due to improved prevention. However, this needs to be investigated further. To analyse HCWs' occupational risk of infection, prospective studies are needed that focus on HCWs in terms of specific work profiles bearing in mind the importance of assessment of personal risk factors for infection. Contact with blood, for example, from NSI, is associated with a risk of infection and continues to be the major threat to the health of HCWs. Targeted prevention measures must be based on the epidemiological detection and evaluation of work-related accidents. Readily accessible reporting and treatment procedures, and the use of safe practices for working with blood, can help to minimise occupational exposure.

Collaborators Melanie Harling.

Contributors CW conceived the study protocol, performed the study selection data extraction, quality assessment and statistical analysis, and wrote the first draft of the manuscript. CP was involved in performing data extraction, quality assessment and statistical analysis and made substantial contributions toward revising the first draft. BL performed the study selection and assessment, and made substantial contributions towards revising the first draft. ML made substantial contributions toward revising the first draft. AN coordinated the study, amended the study protocol, assisted in study selection and statistical analysis, and made substantial contributions toward revising the first draft.

Competing interests None declared.

Provenance and peer review Not commissioned; externally peer reviewed.

Open Access This is an Open Access article distributed in accordance with the Creative Commons Attribution Non Commercial (CC BY-NC 4.0) license, which permits others to distribute, remix, adapt, build upon this work non-commercially, and license their derivative works on different terms, provided the original work is properly cited and the use is non-commercial. See: http://creativecommons.org/ licenses/by-nc/4.0/

\section{REFERENCES}

1 World Health Organization. Prevention and control of viral hepatitis infection: framework for global action. Geneva, 2012:28.

2 Askarian $\mathrm{M}$, Yadollahi $\mathrm{M}$, Kuochak $\mathrm{F}$, et al. Precautions for health care workers to avoid hepatitis B and C virus infection. Int I Occup Environ Med 2011;2:191-8.

3 Te HS, Jensen DM. Epidemiology of hepatitis B and C viruses: a global overview. Clin Liver Dis 2010;14:1-21, vii.

4 Deuffic-Burban $S$, Delarocque-Astagneau E, Abiteboul $D$, et al. Blood-borne viruses in health care workers: prevention and management. J Clin Virol 2011;52:4-10.

5 Nienhaus A, Kesavachandran C, Wendeler D, et al. Infectious diseases in healthcare workers - an analysis of the standardised data set of a German compensation board. J Occup Med Toxicol 2012;7:8.

6 Elseviers MM, Arias-Guillen M, Gorke A, et al. Sharps injuries amongst healthcare workers: review of incidence, transmissions and costs. J Ren Care 2014;40:150-6.

7 Himmelreich $\mathrm{H}$, Rabenau $\mathrm{HF}$, Rindermann $\mathrm{M}$, et al. The management of needlestick injuries. Dtsch Arztebl Int 2013;110:61-7.

8 Kubitschke A, Bahr MJ, Aslan N, et al. Induction of hepatitis C virus (HCV)-specific T cells by needle stick injury in the absence of HCV-viraemia. Eur I Clin Invest 2007;37:54-64.

9 Sulkowski MS, Ray SC, Thomas DL. Needlestick transmission of hepatitis C. JAMA 2002;287:2406-13.

10 Yazdanpanah Y, De CG, Migueres B, et al. Risk factors for hepatitis C virus transmission to health care workers after occupational exposure: a European case-control study. Clin Infect Dis 2005:41:1423-30.

11 Wicker S, Rabenau HF, Haberl AE, et al. Blutübertragbare Infektionen und die schwangere Mitarbeiterin im Gesundheitswesen. Risiko und Präventionsmaßnahmen Blood-borne infections and the pregnant health care worker. Risks and preventive measures. Chirurg 2012;83:136-42.
12 Hofmann F, Kralj N, Beie M. Kanülenstichverletzungen im GesundheitsdienstHäufigkeiten, Ursachen und Präventionsstrategien Needle stick injuries in health care - frequency, causes und preventive strategies. Gesundheitswesen 2002;64:259-66.

13 Dulon M, Nienhaus A. Aktuelle Trends bei Infektionskrankheiten der Beschäftigten im Gesundheitsdienst—2008 bis 2012. In: Nienhaus A, ed. RiRe—Risiken und Ressourcen in Gesundheitsdienst und Wohlfahrtspflege. Heidelberg: Ecomed Medizin, 2014:27-40.

14 Stroup DF, Berlin JA, Morton SC, et al. Meta-analysis of observational studies in epidemiology: a proposal for reporting. Meta-analysis of Observational Studies in Epidemiology (MOOSE) group. JAMA 2000;283:2008-12.

15 [No authors listed]. Public Health Service guidelines for the management of health-care worker exposures to HIV and recommendations for postexposure prophylaxis. Centers for Disease Control and Prevention. MMWR Recomm Rep 1998;47:1-33.

16 Downs SH, Black N. The feasibility of creating a checklist for the assessment of the methodological quality both of randomised and non-randomised studies of health care interventions. J Epidemiol Community Health 1998;52:377-84.

17 Loney PL, Chambers LW, Bennett KJ, et al. Critical appraisal of the health research literature: prevalence or incidence of a health problem. Chronic Dis Can 1998:19:170-6.

18 Higgins JPT, Green S, eds. Cochran handbook for systematic reviews of interventions 4.2.6. Chichester, UK: John Wiley \& Sons, 2006.

$19 \operatorname{Slim} \mathrm{K}$, Nini E, Forestier D, et al. Methodological index for non-randomized studies (minors): development and validation of a new instrument. ANZ J Surg 2003;73:712-16.

20 Vandenbroucke JP, von Elm E, Altman DG, et al. Strengthening the Reporting of Observational Studies in Epidemiology (STROBE): explanation and elaboration. PLOS Med 2007:4:e297.

21 Hahne SJ, Veldhuijzen IK, Wiessing L, et al. Infection with hepatitis B and C virus in Europe: a systematic review of prevalence and cost-effectiveness of screening. BMC Infect Dis 2013;13:181.

22 Mohd Hanafiah K, Groeger J, Flaxman AD, et al. Global epidemiology of hepatitis $C$ virus infection: new estimates of age-specific antibody to HCV seroprevalence. Hepatology 2013;57:1333-42.

23 Egger M, Davey Smith G, Schneider M, et al. Bias in meta-analysis detected by a simple, graphical test. BMJ 1997;315:629-34.

24 Puro V, Petrosillo N, Ippolito G, et al. Occupational hepatitis C virus infection in Italian health care workers. Italian Study Group on Occupational Risk of Bloodborne Infections. Am J Public Health 1995;85:1272-5.

25 Maillard MF, Poynard T, Dubreuil P, et al. Prevalence of serum anti-hepatitis C virus antibodies and risk factors of contamination in the personnel of a hospital in the Paris region. A prospective survey. Gastroenterol Clin Biol 1996;20:1053-7.

26 Cooper BW, Krusell A, Tilton RC, et al. Seroprevalence of antibodies to hepatitis C virus in high-risk hospital personnel. Infect Control Hosp Epidemiol 1992;13:82-5.

27 Ahmetagic S, Muminhodzic K, Cickusic E, et al. Hepatitis C infection in risk groups. Bosn J Basic Med Sci 2006;6:13-17.

28 Daw MA, Elkaber MA, Drah AM, et al. Prevalence of hepatitis $C$ virus antibodies among different populations of relative and attributable risk. Saudi Med J 2002;23:1356-60.

29 Mihaly I, Telegdy L, Ibranyi E, et al. Prevalence, genotype distribution and outcome of hepatitis $C$ infections among the employees of the Hungarian Central Hospital for infectious diseases. J Hosp Infect 2001;49:239-44.

30 Gershon RR, Sherman M, Mitchell C, et al. Prevalence and risk factors for bloodborne exposure and infection in correctional healthcare workers. Infect Control Hosp Epidemiol 2007;28:24-30.

31 Ozsoy MF, Oncul O, Cavuslu S, et al. Seroprevalences of hepatitis B and C among health care workers in Turkey. J Viral Hepat 2003;10:150-6.

32 Klein RS, Freeman K, Taylor PE, et al. Occupational risk for hepatitis C virus infection among New York City dentists. Lancet 1991;338:1539-42.

33 Sermoneta-Gertel $\mathrm{S}$, Donchin $\mathrm{M}$, Adler $\mathrm{R}$, et al. Hepatitis $\mathrm{c}$ virus infection in employees of a large university hospital in Israel. Infect Control Hosp Epidemiol 2001;22:754-61.

34 Thomas DL, Gruninger SE, Siew C, et al. Occupational risk of hepatitis C infections among general dentists and oral surgeons in North America. Am J Med 1996:100:41-5.

35 Struve J, Aronsson B, Frenning B, et al. Prevalence of antibodies against hepatitis $C$ virus infection among health care workers in Stockholm. Scand I Gastroenterol 1994;29:360-2.

36 Braczkowska B, Kowalskan M, Zejda JE, et al. Prevalence and basic determinants of hepatitis $C$ antibodies in medical students in Katowice, Poland. Przeg/ Lek 2006;63:539-42.

37 Fisker N, Mygind LH, Krarup HB, et al. Blood borne viral infections among Danish health care workers--frequent blood exposure but low prevalence of infection. Eur $J$ Epidemiol 2004;19:61-7.

38 Ciorlia LA, Zanetta DM. Hepatitis C in health care professionals: prevalence and association with risk factors. Rev Saude Publica 2007:41:229-35.

39 Moens G, Vranckx R, de Greef $L$, et al. Prevalence of hepatitis $C$ antibodies in a large sample of Belgian healthcare workers. Infect Control Hosp Epidemiol 2000;21:209-12. 
40 Thorburn D, Dundas D, McCruden EA, et al. A study of hepatitis $C$ prevalence in healthcare workers in the West of Scotland. Gut 2001;48:116-20.

41 Djeriri $\mathrm{K}$, Fontana L, Laurichesse $\mathrm{H}$, et al. Seroprevalence of markers of viral hepatitis A, B and C in hospital personnel at the Clermont-Ferrand University Hospital Center. Presse Med 1996;25:145-50.

42 Villate Jl, Corral J, Aguirre C, et al. Hepatitis C virus antibodies in hospital personnel. Med Clin (Barc) 1993;100:766-9.

43 Montella M, Crispo A, Grimaldi M, et al. An assessment of hepatitis C virus infection among health-care workers of the National Cancer Institute of Naples, Southern Italy. Eur J Public Health 2005;15:467-9.

44 Kaabia N, Ben JE, Hannachi N, et al. Prevalence of hepatitis C virus among health care workers in central Tunisia. Med Mal Infect 2009;39:66-7.

45 Irani-Hakime N, Aoun J, Khoury S, et al. Seroprevalence of hepatitis C infection among health care personnel in Beirut, Lebanon. Am J Infect Control 2001;29:20-3.

46 Campello C, Majori S, Poli A, et al. Prevalence of HCV antibodies in health-care workers from northern Italy. Infection 1992;20:224-6.

47 Polish LB, Tong MJ, Co RL, et al. Risk factors for hepatitis C virus infection among health care personnel in a community hospital. Am I Infect Control 1993;21:196-200.

48 Perez Trallero E, Cilla G, Alcorta M, et al. Low risk of acquiring the hepatitis $C$ virus for the health personnel. Med Clin (Barc) 1992;99:609-11.

49 Takahama AJ, Tatsch F, Tannus G, et al. Hepatitis C: incidence and knowledge among Brazilian dentists. Community Dent Health 2005;22:184-7.

50 Trevisan A, Bicciato F, Fanelli $G$, et al. Risk of hepatitis $C$ virus infection in a population exposed to biological materials. Am J Ind Med 1999;35:532-5.

51 Weber C, Coller-Schaub D, Fried R, et al. Low prevalence of hepatitis C virus antibody among Swiss dental health care workers. J Hepatol 2001;34:963-4.

52 Shapiro CN, Tokars Jl, Chamberland ME. Use of the hepatitis-B vaccine and infection with hepatitis B and C among orthopaedic surgeons. The American Academy of Orthopaedic Surgeons Serosurvey Study Committee. J Bone Joint Surg Am 1996:78:1791-800

53 Goetz AM, Ndimbie OK, Wagener MM, et al. Prevalence of hepatitis $C$ infection in health care workers affiliated with a liver transplant center. Transplantation 1995;59:990-4.

54 Ahmed F, Irving WL, Anwar $\mathrm{M}$, et al. Prevalence and risk factors for hepatitis $\mathrm{C}$ virus infection in Kech District, Balochistan, Pakistan: most infections remain unexplained. A cross-sectional study. Epidemiol Infect 2012;140:716-23.

55 Fischer LR, Tope DH, Conboy KS, et al. Screening for hepatitis $C$ virus in a health maintenance organization. Arch Intern Med 2000;160:1665-73.

56 De Mercato R, Guarnaccia D, Ciannella G, et al. Hepatitis C virus among health care workers. Minerva Med 1996;87:501-4.

57 Olubuyide IO, Ola SO, Aliyu B, et al. Prevalence and epidemiological characteristics of hepatitis B and $C$ infections among doctors and dentists in Nigeria. East Afr Med J 1997;74:357-61.

58 al-Sohaibani MO, al-Sheikh EH, al-Ballal SJ, et al. Occupational risk of hepatitis B and C infections in Saudi medical staff. J Hosp Infect 1995;31:143-7.

59 Soni PN, Tait DR, Kenoyer DG, et al. Hepatitis C virus antibodies among risk groups in a South African area endemic for hepatitis B virus. J Med Virol 1993;40:65-8.

60 Oguchi H, Miyasaka M, Tokunaga S, et al. Hepatitis virus infection (HBV and HCV) in eleven Japanese hemodialysis units. Clin Nephrol 1992;38:36-43.

61 Nakashima K, Kashiwagi S, Hayashi J, et al. Low prevalence of hepatitis C virus infection among hospital staff and acupuncturists in Kyushu, Japan. J Infect 1993:26:17-25.

62 Fujiyama S, Kawano S, Sato $S$, et al. Prevalence of hepatitis $C$ virus antibodies in hemodialysis patients and dialysis staff. Hepatogastroenterology 1992;39:161-5.

63 Germanaud J, Barthez JP, Causse X. The occupational risk of hepatitis C infection among hospital employees. Am J Public Health 1994;84:122.

64 Jindal $N$, Jindal $M$, Jilani $N$, et al. Seroprevalence of hepatitis $C$ virus (HCV) in health care workers of a tertiary care centre in New Delhi. Indian J Med Res 2006;123:179-80.
65 Kuo MY, Hahn L, Hong CY, et al. Low prevalence of hepatitis C virus infection among dentists in Taiwan. J Med Virol 1993;40:10-13.

66 Zaaijer HL, Appelman P, Frijstein G. Hepatitis C virus infection among transmissionprone medical personnel. Eur J Clin Microbiol Infect Dis 2012;31:1473-7.

67 Zuckerman J, Clewley G, Griffiths P, et al. Prevalence of hepatitis C antibodies in clinical health-care workers. Lancet 1994;343:1618-20.

68 Jochen $A B$. Occupationally acquired hepatitis $C$ virus infection. Lancet 1992:339:304.

69 el Gohary A, Hassan A, Nooman Z, et al. High prevalence of hepatitis C virus among urban and rural population groups in Egypt. Acta Trop 1995;59:155-61.

70 Polywka S, Laufs R. Hepatitis C virus antibodies among different groups at risk and patients with suspected non-A, non-B hepatitis. Infection 1991;19:81-4.

71 Hindy AM, Abdelhaleem ES, Aly RH. Hepatitis B and C viruses among Egyptian dentists. Egypt Dent J 1995;41:1217-26

72 Khan S, Attaullah S, Ayaz S, et al. Molecular epidemiology of HCV among health care workers of khyber pakhtunkhwa. Virol I 2011;8:105.

73 Mijakoski D, Karadzinska-Bislimovska J, Stikova E, et al. Occupational sharp injuries and biological markers of hepatitis $B$ and hepatitis $C$ viral infection in nurses. Macedonian J Med Sci 2012;4:417-27.

74 Kondili LA, Ulqinaku D, Hajdini M, et al. Hepatitis B virus infection in health care workers in Albania: a country still highly endemic for HBV infection. Infection 2007:35:94-7.

75 Libanore M, Bicocchi R, Ghinelli F, et al. Prevalence of antibodies to hepatitis C virus in Italian health care workers. Infection 1992:20:50.

76 Mujeeb SA, Khatri Y, Khanani R. Frequency of parenteral exposure and seroprevalence of HBV, HCV, and HIV among operation room personnel. J Hosp Infect 1998;38:133-7.

77 Sarkari B, Eilami O, Khosravani A, et al. High prevalence of hepatitis C infection among high risk groups in Kohgiloyeh and Boyerahmad Province, Southwest Iran. Arch Iran Med 2012;15:271-4.

78 Vardas E, Ross MH, Sharp G, et al. Viral hepatitis in South African healthcare workers at increased risk of occupational exposure to blood-borne viruses. J Hosp Infect 2002;50:6-12.

79 Shoaei P, Lotfi N, Hassannejad R, et al. Seroprevalence of hepatitis C infection among laboratory health care workers in Isfahan, Iran. Int J Prev Med 2012;3:S146-9.

80 De Luca M, Ascione A, Vacca C, et al. Are health-care workers really at risk of HCV infection? Lancet 1992:339:1364-5.

81 Sepkowitz KA. Occupationally acquired infections in health care workers. Part II. Ann Intern Med 1996:125:917-28.

82 Lanphear BP. Transmission and control of bloodborne viral hepatitis in health care workers. Occup Med (Lond) 1997;12:717-30.

83 Henderson DK. Managing occupational risks for hepatitis C transmission in the health care setting. Clin Microbiol Rev 2003;16:546-68.

84 Singh K. Laboratory-acquired infections. Clin Infect Dis 2009;49:142-7.

85 Phillips EK, Conaway MR, Jagger JC. Percutaneous injuries before and after the Needlestick Safety and Prevention Act. N Engl J Med 2012:366:670-1.

86 Riddell LA, Sherrard J. Blood-borne virus infection: the occupational risks. Int J STD AIDS 2000:11:632-9.

87 Baldo V, Baldovin T, Trivello R, et al. Epidemiology of HCV infection. Curr Pharm Des 2008:14:1646-54.

88 Butsashvili M, Kamkamidze G, Kajaia M, et al. Occupational exposure to body fluids among health care workers in Georgia. Occup Med (Lond) 2012;62:620-6.

89 Goniewicz M, Wloszczak-Szubzda A, Niemcewicz M, et al. Injuries caused by sharp instruments among healthcare workers--international and Polish perspectives. Ann Agric Environ Med 2012:19:523-7.

90 Shah SM, Bonauto D, Silverstein B, et al. Workers' compensation claims for needlestick injuries among healthcare workers in Washington State, 1996-2000. Infect Control Hosp Epidemiol 2005;26:775-81.

91 Larney S, Kopinski H, Beckwith CG, et al. Incidence and prevalence of hepatitis C in prisons and other closed settings: results of a systematic review and meta-analysis. Hepatology 2013;58:1215-24. 